\title{
Significados ideacionales asociados a la comunidad gay en textos de ciberprensa chilena
}

\author{
Ideational meanings associated to the gay community in texts from the \\ Chilean cyber press
}

Recibido: Noviembre 2019 Aceptado: Junio 2020 Publicado: Diciembre 2020

\author{
Claudio Araya Seguel \\ Universidad de Santiago de Chile, Chile \\ claudio.araya@usach.cl
}

\begin{abstract}
Resumen: Este artículo muestra la participación de los actores sociales de la comunidad gay en textos de ciberprensa chilena entre los años 2012-2017. Estos textos fueron tomados en el contexto sociohistórico de hitos significativos para la comunidad gay: Caso Zamudio, Ley Antidiscriminación, Acuerdo de Unión Civil y discusión sobre el Matrimonio Igualitario. La participación de esos actores sociales es explorada desde el sistema de IDEACIÔN adscrito a la lingüística sistémico funcional (LSF). Los procesos asociados a las entidades colectivas e individuales que representan a la comunidad gay en el corpus configuran fenómenos socioculturales vinculados a la gestión e incidencia política de esas entidades en los cambios sociales. El rol social de la comunidad gay ilustra reajustes en las relaciones de poder y que pueden sintetizarse en la categoría ideológica "gay político" y sus variantes "víctima" y "activista".
\end{abstract}

Palabras claves: Estudios críticos del discurso - IDEACIÓN - Comunidad gay Ciberprensa - Hitos

Citación: Araya Seguel, C. (2020).Significados ideacionales asociados a la comunidad gay en textos de ciberprensa chilena. Logos: Revista de Lingüística, Filosofía y Literatura, 30(2), 331-348. doi. org/10.15443/RL3025

Dirección Postal: Av. Las Sophoras 175, Estación Central. Santiago, Chile 


\begin{abstract}
This article describes the participation of social actors from the gay community in the Chilean cyber press between 2012-2017. These texts were gathered in the socio-historical context of significant milestones for the gay community: the Zamudio Case, Anti-discrimination Law, Civil Union Agreement and discussion on Equal Marriage. The participation of these social actors is explored using the IDEATIONAL system from functional systemic linguistics (FSL). The processes associated with the collective and individual actors that represent the gay community in the corpus shape socio-cultural phenomena linked to the political work and influence of these actors in social changes. The social role of the gay community evidences realignments of power relations which can be synthesized in the ideological category "political gay" and its variants, "victim" and "activist".
\end{abstract}

Keyswords: Critical discourse studies - IDEATION - Gay community - Cyber press - Milestones

\title{
1. Introducción
}

Entre los años 2012 y 2017 se produjeron una serie de hitos que expresan el cambio social en Chile respecto al tratamiento a la comunidad gay. A partir del asesinato homofóbico de Daniel Zamudio (2012), se han desencadenado una serie de legislaciones y discusiones públicas acerca de la situación de la comunidad gay en Chile. Luego de dicho asesinato se promulgó la Ley Antidiscriminación (2012) y la Ley de Acuerdo de Unión Civil (2015) y, además, se intensifica la discusión pública acerca del Matrimonio Igualitario (2017). Estos eventos abrieron el camino para otras demandas relevantes de la comunidad LGBTI, de manera más amplia, como la urgencia de la Ley de Identidad de Género (LIG) y la modificación de la ley de adopción. Estos eventos son considerados hitos en tanto impulsaron la discusión pública respecto a la histórica condena a la comunidad gay y, al mismo tiempo, movilizaron la gestión política de las organizaciones de diversidad sexual. Tanto la discusión pública generada como la gestión política de las organizaciones de diversidad sexual contribuyeron a abrir fisuras en el discurso hegemónico heteronormativo (Pollak, 1987; Preciado, 2002; Wittig, 2016) que ha validado históricamente la exclusión de la diferencia en materia de identidad sexual y de género.

De esta forma, los hitos revelan cambios sociales en la sociedad chilena, por lo cual es clave examinar si esos cambios sociales se reflejan en el discurso de ciberprensa. En la actualidad, la ciberprensa cumple un papel importante en la configuración del mundo social, en tanto contribuye a construirlo, deconstruirlo y reconstruirlo. Esto significa que el pensamiento social circula en los ciberperiódicos (Trejo, 1996; Castells, 2006; Lario, 2008; y en medios de prensa digital que han abandonado el soporte papel o que simplemente no lo emplean (Cabrera, 2010). A su vez, probablemente debido a la masificación de los dispositivos electrónicos con conexión a internet, el acceso y consumo de dichos medios ha aumentado notablemente en desmedro del acceso, consumo y lectoría de periódicos tradicionales.

Por tanto, el objetivo de este estudio es explorar el rol asignado a la comunidad gay en el flujo experiencial desplegado en textos de ciberprensa chilena. 


\section{Fundamentos teóricos}

Importancia de los significados ideacionales en los Estudios críticos del discurso.

En este trabajo se adopta la perspectiva de los Estudios críticos del discurso, en tanto se aborda el problema social de la histórica discriminación contra la comunidad gay (Zubiaur, 2007; Fone 2008; Contardo, 2011; Chamocho, 2012). Ese problema social está vinculado a las relaciones de poder dentro de la estructura social. Desde la perspectiva de Fairclough (1992, 1995, 2013, 2014), esas relaciones de poder se realizan en un equilibrio inestable, a través de la integración y no necesariamente mediante la imposición del poder hegemónico encarnado por la trama institucional. En el caso del problema social de la discriminación hacia la comunidad gay, la trama institucional ${ }^{1}$ (Fairclough, 1992, 1995, 2013; Fone, 2008; Chamocho, 2012, Alegre, 2017) ha desplegado históricamente un discurso condenatorio basado en un régimen heteronormado (Pollak, 1987; Preciado, 2002; Wittig, 2016). Este régimen ha contribuido a discriminar y marginalizar a las sexualidades disidentes, al considerarlas perversiones o desviaciones de la norma y libretos ancestrales (Alegre, 2017) que regulan las prácticas sexuales. Frente a ese discurso condenatorio, la lucha política de las organizaciones de diversidad sexual ha puesto en crisis al régimen heteronormado y ha logrado visibilizar el problema social de la discriminación social por orientación sexual e identidad de género. Este problema social se ha constituido como uno de los parámetros clave para evaluar el estado de las democracias (Martel, 2013; Araya, 2019), en tanto se sitúa en la órbita de los derechos humanos.

Este estudio crítico del discurso orientado lingüísticamente, se posiciona dentro de la Lingüística sistémico funcional (LSF), pues se trata de una teoría que concibe el lenguaje como un sistema sociosemiótico estratificado. Esa estratificación integra los niveles lingüísticos y contextuales. La integración de los estratos lingüísticos y contextuales implica que el lenguaje, en tanto sistema, corresponde a una red de opciones desde donde los hablantes /escritores seleccionan recursos para construir significados a partir de la configuración contextual (Halliday \& Matthiessen, 2014). Dicho en otros términos, los recursos lingüísticos están moldeados por la configuración contextual. Por tanto, si el lenguaje es fuertemente sensible a las características de los contextos sociales y culturales, la LSF contribuye a explorar la relación entre el cambio social y el cambio discursivo (Fairclough, 1992, 2013).

Dentro del ámbito de la Lingüística sistémico funcional, la metafunción ideacional corresponde a la expresión discursiva de la experiencia externa e interna en el mundo. A través del lenguaje instanciado en el texto organizamos la experiencia en el mundo social, primero en la cláusula y luego en el despliegue del texto. La metafunción ideacional, en el estrato semántico discursivo, se realiza a través del sistema de IDEACIÓN. El aporte del sistema de IDEACIÓN en la exploración de los textos radica en que distingue aspectos de la experiencia en el mundo, tales como entidades, procesos y circunstancias. Este aporte permite realizar un mapeo del mundo social para identificar el rol asignado a los actores sociales de la comunidad gay en los textos.

Al situarnos en el estrato semántico discursivo buscamos la interpretación del discurso más allá de la cláusula. Esto significa focalizarse en los recursos desde una cláusula a otra en su despliegue como texto, lo cual implica abordar el texto como actividad social en la que se negocian los significados (Martin, 2003; Martin \& White, 2005; Martin \& Rose, 2007; White, 2010; Oteíza \& Pinuer, 2012). Al analizar los recursos de construcción de significados en la representación del despliegue del texto, estamos considerando la secuencia de significados comprendidos en él. Además, la exploración del discurso permitirá -en el sentido que lo propone la LSF- interpretar el texto como expresión reveladora de un contexto social y cultural.

El sistema de IDEACIÓN se enfoca en el contenido del discurso en cuanto a qué actividades se realizan y cómo los participantes describen y clasifican esas actividades. En efecto, se ocupa de cómo se organiza la experiencia respecto a las personas, las cosas y las actividades. Aspectos clave de este sistema son las secuencias de actividades y la descripción y clasificación de las personas y las cosas.

Logos: Revista de Lingüística, Filosofía y Literatura 30(2) 
Al situarnos en el estrato semántico discursivo, podemos reconocer dos tipos de patrones de significado ideacional: las relaciones de conjunción realizadas a través del sistema de conjunción y las relaciones léxicas que construyen el campo de un texto y que se expresan en el sistema de IDEACIÓN. El sistema de CONJUNCIÓN tiene que ver con las relaciones lógicas que se dan entre las cláusulas para el despliegue de la experiencia en una serie de actividades. Mientras que el sistema de IDEACIÓN corresponde a las relaciones semánticas entre los elementos que intervienen en la construcción de la experiencia, tales como personas, cosas, procesos, lugares y cualidades.

Como se indicó, uno de los patrones de significado ideacional corresponde a las relaciones léxicas. Se pueden reconocer tres grupos de relaciones de ese tipo: las relaciones taxonómicas, las relaciones nucleares y la secuencia de actividades (Martin, 1992: 271; Martin \& Rose, 2007: 73). En este estudio optamos por efectuar el análisis a partir de las relaciones taxonómicas por cuanto son más productivas para ilustrar la relación entre el cambio social y discursivo. Las relaciones léxicas en el corpus estudiado configuran procesos o fenómenos socioculturales relevantes para comprender la incidencia de la comunidad gay en el mundo social configurado en el discurso.

Las relaciones taxonómicas corresponden a un recurso ideativo que revela la configuración del mundo social en el texto. Dentro de ese mundo social encontraremos participantes que, en el caso de nuestro corpus, podrían instanciarse a través de expresiones tales como "organizaciones de diversidad sexual", "gay", "homosexualidad", entre otras. Esos elementos léxicos que dan cuenta del mundo social en el que opera el texto, en el caso de este estudio, dependerán del hito que esté asociado al texto analizado. De esta manera, los ítemes léxicos que se instancian en el texto constituirían un mapeo del mundo social y, en este sentido, podrían resultar productivos en términos del análisis del discurso de ciberprensa referido a la comunidad gay.

Las taxonomías quepermiten organizarla experiencia del mundo social pueden expresarsea través de distintos tipos de relaciones léxicas. Martin (1992) establece dos grandes tipos de relaciones taxonómicas: subordinación y composición. Las relaciones taxonómicas por subordinación se basan en el criterio de subclasificación e incluyen los conceptos de hiperonimia, hiponimia y cohiponimia. En cambio, las relaciones taxonómicas por composición se organizan a partir del criterio parte /todo, por tanto, consideran los conceptos de meronimia y co-meronimia. Martin (1992) propone una serie de criterios para establecer las relaciones taxonómicas en inglés. En el caso de las relaciones de subordinación pueden realizarse típicamente a partir de clase, tipo, especie, estilo, familia, género, grado, categoría, forma, raza, marca, casta. Por su parte, las relaciones de composición pueden realizarse desde parte, contenido, ingrediente, miembro, constituyente, estrato, rango, plano, extracto, pieza, segmento, porción, medida.

Las relaciones taxonómicas por subordinación se pueden manifiestar como clase y dentro de esta categoría podemos distinguir clase miembro y co-clase. Otros tipos de relaciones léxicas asociadas a la taxonomía son la repetición y la sinonimia. En el caso de la primera, un ítem léxico se reitera incluso a través de transcategorizaciones. En el caso del corpus, es común observar expresiones como "homosexual", "homosexualidad" "homosexualismo". A propósito del hito "matrimonio igualitario" en el corpus aparecen expresiones como "matrimonio", "casarse" o "casado", curiosamente, cuando se alude al AUC (Acuerdo de Unión Civil). La sinonimia, por su parte, implica similares significados experienciales expresados a través de distintos ítemes léxicos. En el corpus, por ejemplo, algunas expresiones sinónimas dan cuenta de cómo se construyen experiencialmente los hitos y revelan ciertas concepciones en torno a algunas instituciones: "matrimonio" en algunos casos es empleado como sinónimo de AUC. Otros ejemplos observados son: "matrimonio igualitario" y "matrimonio homosexual".

Las relaciones léxicas también pueden operar a nivel de contraste a través de la antonimia. Algunas unidades léxicas que presentan significados contrarios y que se registran en el corpus son las siguientes: respecto al matrimonio igualitario se establece la distinción entre "matrimonio normal" y "matrimonio anormal"; "vínculo normal" y "vínculo anormal". Por su parte, las relaciones léxicas entre ítemes léxicos con significados complementarios no 
necesariamente son antónimos (Martin \& Rose, 2007). En el corpus, en relación con el caso del crimen de Daniel Zamudio (2012) aparecen expresiones "víctima" y "victimarios".

Dentro de las relaciones léxicas de contraste podemos reconocer las denominadas series y ciclos. Las series incorporan escalas semánticas como en el caso de "idolatrar"-"adorar"-"amar"-"querer""despreciar"-"odiar". Los ciclos apuntan, por ejemplo, a los días de la semana, a la trayectoria de vida de un individuo (infancia, adolescencia, adultez, vejez) entre otras posibilidades.

Desde la perspectiva de las relaciones por composición, existen las relaciones léxicas que se establecen desde la asociación todo-parte y co-parte. Las entidades más generales que intervienen en el plano experiencial como personas, cosas y lugares se componen de partes más pequeñas como en los casos de cuerpo-piernas-pies-dedos-uñas (todo-parte) y piernas-brazos-dedos-ojos-cara (co-partes). Las relaciones taxonómicas y su potencial de realización se aprecian en el siguiente diagrama tomado de Martin y Rose (2007:81)2:

Figura 1. Red de relaciones taxonómicas (Martin y Rose, 2007:81)

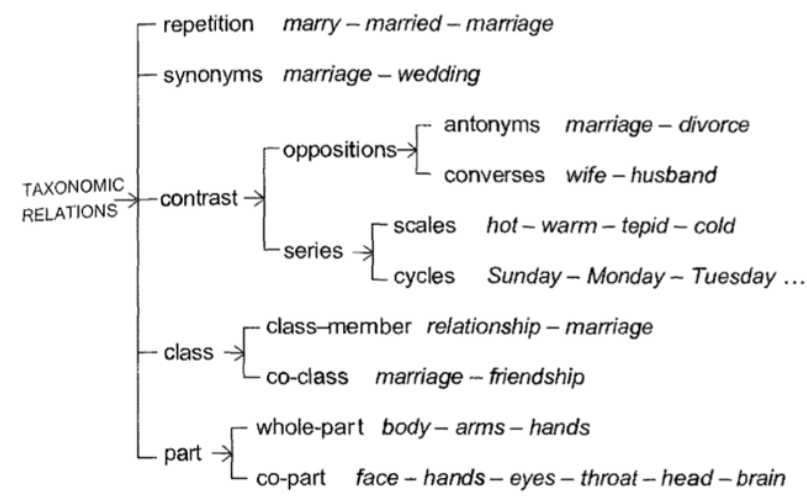

El recurso analítico de las relaciones taxonómicas correspondientes al sistema de IDEACIÓN, contribuye a identificar las selecciones léxicas que mapean el mundo social constituido en el discurso examinado y, de esta manera, complementar el análisis valorativo realizado preliminarmente. Así daremos cuenta de la construcción de los posicionamientos ideológicos de los hablantes/escritores, por una parte, y de la conformación del campo a través de la elaboración del flujo de la experiencia.

En el nivel de la metafunción ideacional, específicamente en el sistema de IDEACIÓN, la representación discursiva de la experiencia en el mundo se puede expresar también a través de los tipos de entidades. Martin y Rose (2007) distinguen dos tipos de entidades: concretas y abstractas. Estas categorías, según los autores, dependerán de las características del campo en cuanto a su grado de especialización. Según los autores, en el campo de las actividades diarias donde opera el sentido común, es posible detectar entidades concretas. Mientras que en campos especializados ligados -por ejemplo- a una disciplina o área del conocimiento, probablemente encontremos entidades abstractas. Como ya he señalado, el corpus fue tomado a partir de hitos significativos para la comunidad gay (Caso Zamudio, Ley Antidiscriminación, Ley de Acuerdo de Unión Civil y discusión sobre Matrimonio Igualitario), los que están asociados a legislaciones. De esta manera, el campo de los textos corresponde a la política, en gran medida, en su dimensión legislativa y, por tanto, abstracta.

\section{Metodología}

En primera instancia, se realizó un análisis valorativo de 56 textos de las versiones digitales de los medios The Clinic, La Tercera, La Segunda, La Nación, La Cuarta, Emol, El Mostrador y 
El Ciudadano. Los textos fueron seleccionados a partir de los siguientes criterios: i) cercanía temporal con el hito, ii) elaboración del hito y iii) relación intertextual basada en el contenido. A su vez, se consideraron aquellos medios en formato digital por cuanto representaron de forma más completa y sistemática los hitos. La excepción es El Mostrador, medio que no dispone de versión impresa. Esos criterios permitieron acotar la fuente de los textos al no incluir otros portales de noticias, por ejemplo, de radios o canales de televisión.

El análisis valorativo preliminar permitió identificar a los actores sociales representativos de la comunidad gay, tanto como entidades discursivas evaluadas como voces que evalúan. Los actores sociales no aparecen representados en todos los textos examinados, pero sí en todos los medios digitales incorporados en el estudio.

Los actores sociales representativos de la comunidad gay corresponden a las entidades colectivas "Víctimas", "Movilh" e "Iguales"; y a las entidades individuales Rolando Jiménez y Luis Larraín, principales dirigentes del Movilh e Iguales, respectivamente. Estas entidades colectivas e individuales quedan ilustradas en el siguiente cuadro:

Tabla 1. Entidades humanas representadas en el corpus.

\begin{tabular}{|l|l|}
\hline \multicolumn{2}{|c|}{ Actores sociales pertenecientes a la comunidad gay } \\
\hline \multicolumn{1}{|c|}{ Individuales } & \multicolumn{1}{c|}{ Colectivos } \\
\hline $\begin{array}{l}\text { Rolando Jiménez } \\
\text { Luis Larraín }\end{array}$ & $\begin{array}{l}\text { Movilh } \\
\text { Iguales } \\
\text { Víctimas (Daniel Zamudio, trabajador uruguayo, } \\
\text { pareja lésbica, funcionaria de INJUV }\end{array}$ \\
\hline
\end{tabular}

A continuación, el análisis ideacional se focaliza en los procesos y cualidades asociados a los actores sociales que representan a la comunidad gay en el corpus. A partir de esos procesos y cualidades asignadas, se construyen las relaciones taxonómicas que configuran procesos y fenómenos socioculturales relevantes para comprender el rol de dichos actores políticos. Esas relaciones taxonómicas se presentan en tablas numeradas e incluyen los segmentos textuales en los cuales se aprecia la representación lingüística de las entidades humanas individuales y colectivas de la comunidad gay y su asociación con procesos y cualidades.

\section{Análisis y principales resultados}

\subsection{Identidad sexual de Daniel Zamudio}

En el ciberperiódico The Clinic, desde las voces incorporadas al texto, se acentúa en el temor experimentado por el muchacho frente a la eventual reacción negativa de su entorno por su condición sexual. Por ello, en la tabla siguiente incluyo las voces desde donde proviene la construcción discursiva de la identidad sexual de Zamudio. Los procesos de las instancias textuales "siempre decía que no era gay" y "puede aceptarlo a los 17", se relacionan por antonimia y construyen la dificultad para aceptar su condición sexual. Este contraste léxico da luces de la fuerte resistencia interior del muchacho a develar su identidad sexual y su temor frente a un entorno percibido como hostil a su diferencia. Por su parte, los procesos materiales ("cocina", "se mira al espejo") y mentales ("le gustan las cremas", "le encanta dibujar"), empleados por su madre constituyen para ella indicadores reveladores de su verdadera identidad. Esos procesos relacionados por co-hiponimia aportan significados identitarios que acentúan su condición sexual no normada, desde concepciones tradicionales de género. La tabla 2 ilustra las relaciones taxonómicas que configuran la identidad sexual de Daniel Zamudio ${ }^{5}$. 
Tabla 2. Identidad sexual de Daniel Zamudio

\begin{tabular}{|c|c|c|c|}
\hline \multicolumn{4}{|c|}{ Identidad sexual } \\
\hline & Instancias textuales & Relación taxonómica & Voces \\
\hline \multirow{2}{*}{ Daniel Zamudio } & $\begin{array}{l}\text { Siempre decía que no } \\
\text { era gay } \\
\text { Puede aceptarlo a los } 17\end{array}$ & Antónimos & $\begin{array}{l}\text { Naty, amiga de Zamudio } \\
\text { Voz autoral }\end{array}$ \\
\hline & $\begin{array}{l}\text { Cocina } \\
\text { Se mira al espejo } \\
\text { Le gustan las cremas } \\
\text { Le encanta dibujar }\end{array}$ & $\begin{array}{c}\text { Hiperónimo } \\
\text { Indicadores } \\
\text { Co-hipónimos } \\
\text { (tipos de indicadores) }\end{array}$ & $\begin{array}{l}\text { Jaqueline Vera, madre } \\
\text { de Zamudio }\end{array}$ \\
\hline
\end{tabular}

\subsection{Identidad social de Daniel Zamudio}

A esos rasgos identitarios provenientes de las voces de la madre y su amiga Naty, realizados mediante los procesos materiales y mentales, se suman otros rasgos identitarios procedentes de la voz de su padre. La voz del padre subraya las conductas erráticas del joven y su reclamo de afecto. Las instancias "vivió un mundillo" y "se enamoró de un cabro con poder adquisitivo" incluyen procesos ("vivióo" y "se enamoró") que se refieren a que Zamudio estaba engañado, no tenía conciencia de estar en un mundo que no le correspondía, desde la perspectiva del padre. En ese mundo habitado por Zamudio, según su padre, había exceso de alcohol y, por ello, perdía trabajos ("perdía trabajos por el copete"). Estos procesos que construyen los errores del muchacho se relacionan por co-hiponimia, en tanto corresponden a tipos de actividades reveladores de la dimensión identitaria del muchacho.

Iván Zamudio, padre de Daniel, sostiene que el muchacho vivía engañado, además, en cuanto a supuestos sentimientos de rechazo por parte de su padre. Esto se aprecia en las instancias "se me acercaba", "me decía que le hiciera cariño" que contienen procesos materiales y verbales que dan cuenta del reclamo de afecto por parte del joven hacia su padre. Esos procesos configuran las fases que componen la búsqueda de afecto por parte de Daniel Zamudio. En la tabla 3 se pueden apreciar los procesos que construyen la identidad social de Daniel Zamudio.

Tabla 3. Identidad social de Daniel Zamudio

\begin{tabular}{|c|c|c|c|}
\hline \multicolumn{4}{|c|}{ Identidad social en su entorno familiar } \\
\hline & Instancias textuales & Relaciones taxonómicas & Voz \\
\hline Daniel Zamudio & $\begin{array}{l}\text { Vivió un mundillo } \\
\text { Se enamoró de un cabro con } \\
\text { poder adquisitivo } \\
\text { Perdía trabajos por el copete } \\
\text { Se me acercaba } \\
\text { Me decía que le hiciera cariño }\end{array}$ & $\begin{array}{c}\text { Hiperónimo } \\
\text { Actividades } \\
\text { Co-hipónimos (tipos de } \\
\text { actividades) } \\
\text { Composición } \\
\text { Fases en la búsqueda de afecto }\end{array}$ & Padre \\
\hline
\end{tabular}

Las voces de representantes de organizaciones de diversidad sexual en Emol.com acentúan el carácter homofóbico del crimen. La homofobia sufrida por Zamudio se configura en tres dimensiones que conforman una trayectoria: un carácter congénito ("su único pecado fue haber nacido como nació"), la diferencia ("no hizo nada más que tener una condición sexual distinta") y la representación social ("simboliza la homofobia"). De este modo, los procesos despliegan una trayectoria de la homofobia. Las dos primeras instancias podrían corresponder a perífrasis verbales que funcionan como procesos relacionales y como tales introducen la cualidad de Zamudio causante de la brutal agresión. 
La tabla 4 da cuenta de la taxonomía de procesos que configuran la trayectoria de la homofobia desde la voz de Jaime Parada, vocero del Movilh.

Tabla 4. Daniel Zamudio como víctima de la homofobia

\begin{tabular}{|c|l|l|l|}
\hline \multicolumn{4}{|c|}{ Víctima de la Homofobia } \\
\hline \multirow{4}{*}{ Daniel Zamudio } & \multicolumn{1}{|c|}{ Instancias textuales } & \multicolumn{1}{c|}{ Relaciones taxonómicas } & \multicolumn{1}{c|}{ Voz } \\
\cline { 2 - 5 } & $\begin{array}{l}\text { Fue haber nacido como nació } \\
\text { No hizo nada más que tener } \\
\text { una condición sexual distinta } \\
\text { Simboliza la homofobia }\end{array}$ & $\begin{array}{l}\text { Composición: fases de una } \\
\text { trayectoria homofóbica } \\
\text { (caráctercongénito,la diferencia } \\
\text { sexual, representación social) }\end{array}$ & $\begin{array}{l}\text { Jaime Parada, } \\
\text { Vocero devilh } \\
\text { Sovil }\end{array}$ \\
\hline
\end{tabular}

A pesar de la crueldad del ataque y sus consecuencias fatales, algunas voces de representantes de organizaciones de diversidad sexual y las propias voces autorales asignan un valor positivo al caso de Daniel Zamudio. Para esas voces, el ataque y muerte del muchacho produce efectos positivos en la sociedad chilena. Esos efectos positivos se construyen en La Cuarta a través de procesos conjugados en pasado compuesto y perfecto ("ha despertado la solidaridad", "ha provocado algo hermoso") y en La Tercera en condicional que funciona en sentido de acción completamente realizada ("se convertiría en un ícono"). Estos procesos representan tipos de efectos sociales generados por el crimen de Zamudio, por lo cual se relacionan por co-hiponimia, tal como se ilustra en la tabla 5:

Tabla 5. Efectos sociales del ataque contra Daniel Zamudio

\begin{tabular}{|c|l|c|c|}
\hline \multicolumn{4}{|c|}{ Efectos sociales del ataque } \\
\hline \multirow{4}{*}{ Daniel Zamudio } & \multicolumn{1}{|c|}{ Instancias textuales } & Relaciones taxonómicas & \multicolumn{1}{c|}{ Voces } \\
\cline { 2 - 4 } & $\begin{array}{l}\text { Ha despertado solidaridad } \\
\text { Ha provocado algo hermoso }\end{array}$ & $\begin{array}{l}\text { Hipernónimo: Efectos sociales } \\
\text { Co-hipónimos: tipos de efectos }\end{array}$ & Rolando Jiménez \\
\cline { 2 - 2 } & Se convertiría en un ícono & & Voz autoral \\
\hline
\end{tabular}

Los procesos materiales empleados por la madre de Zamudio al referirse a lo que considera mentiras difundidas por la serie de televisión sobre la vida de su hijo, refuerzan representaciones discursivas alineadas con históricas concepciones condenatorias hacia los gays, asociados a promiscuidad e interés por engañar y aprovecharse de las mejores condiciones económicas y sociales de otros ("salía bailando en la disco, como haciendo propaganda a la gente que tenía plata", "estaba buscando una persona con dinero", "besándose con unos y con otros"). Estos procesos materiales se relacionan por co-hiponimia y aluden a distintos tipos de actividades exhibidas por la serie, las cuales, según la madre del joven, son mentiras, como lo ilustra la tabla 6:

Tabla 6. Actividades visibilizadas por la serie de TV sobre Daniel Zamudio.

\begin{tabular}{|c|l|c|c|}
\hline \multicolumn{4}{|c|}{ Actividades visibilizadas por la serie de TV } \\
\hline \multirow{5}{*}{ Daniel Zamudio } & \multicolumn{1}{|c|}{ Instancias textuales } & Relaciones taxonómicas & Voz \\
\cline { 2 - 4 } & $\begin{array}{l}\text { Salía bailando en la disco } \\
\text { Como haciendo propaganda a la } \\
\text { gente que tenía plata } \\
\text { Estaba buscando una persona } \\
\text { con dinero } \\
\text { Besándose con unos y con otros }\end{array}$ & $\begin{array}{c}\text { Hiperónimo } \\
\text { Actividades exhibidas por } \\
\text { la serie } \\
\text { Co-hipónimos. } \\
\text { Tipos de actividades }\end{array}$ & $\begin{array}{c}\text { Jaqueline } \\
\text { Vera, madre } \\
\text { de Zamudio }\end{array}$ \\
\hline
\end{tabular}


Esos procesos materiales expresados por la voz de la madre de Zamudio aparecen solamente en el medio de ciberprensa La Cuarta. Este es el único medio que se refiere al estreno de la serie "Zamudio: perdidos en la noche" debido, probablemente, a que su línea editorial otorga especial tratamiento a temas de espectáculo.

\subsection{Rol político de otras víctimas}

El crimen de Daniel Zamudio no solo impulsó la legislación contra la discriminación, sino que también reveló otros casos de violencia contra personas de la diversidad sexual, aunque no todos ellos fueron visibilizados por todos los medios de ciberprensa incluidos en este estudio.

El medio de ciberprensa La Segunda da cuenta de la primera demanda por Ley Antidiscriminación interpuesta por una pareja de mujeres. La tabla 7 muestra las taxonomías que organizan la representación de la pareja.

Tabla 7. Primeras denunciantes por Ley Antidiscriminación

\begin{tabular}{|l|l|l|c|}
\hline \multicolumn{3}{|c|}{ Primeras denunciantes } \\
\hline \multirow{5}{*}{ Pareja lésbica } & \multicolumn{1}{|c|}{ Instancias textuales } & \multicolumn{1}{|c|}{$\begin{array}{c}\text { Relaciones } \\
\text { taxonómicas }\end{array}$} & \multirow{2}{*}{ Voz } \\
\cline { 2 - 3 } & $\begin{array}{l}\text { Pareja de lesbianas } \\
\text { Pareja de jóvenes lesbianas }\end{array}$ & Clase/subclase & \multirow{2}{*}{ Voutoral } \\
\cline { 2 - 3 } & $\begin{array}{l}\text { Pamela Zapata (23) y Carla de la Fuente } \\
\text { (22) }\end{array}$ & Subclase/miembros & \\
\cline { 2 - 3 } & $\begin{array}{l}\text { Las demandantes } \\
\text { Ambas jóvenes }\end{array}$ & Facetas & \\
\hline
\end{tabular}

En el cuadro precedente, observamos que desde la voz autoral se representa discursivamente a la pareja a través de relaciones de clase-subclase ("pareja de lesbianas", "pareja de jóvenes lesbianas"), de subclase-miembros ("Pamela Zapata y Carla de la Fuente"), sus rasgos etarios y facetas ("ambas jóvenes", "las demandantes"). Este último recurso de nominalización ("demandantes") alude a la acción subyacente emprendida por la pareja, esto es, exigir respeto apelando a la nueva legislación antidiscriminación. Además, la nominalización del proceso "denunciar" se alinea con las valoraciones de juicio por tenacidad advertidas desde el análisis evaluativo preliminar ("demandaron al motel Marín 014").

Desde la perspectiva de los procesos asociados a Camila Castillo, funcionaria del INJUV, en el cuadro siguiente queda en evidencia cómo la voz autoral en La Nación destaca las acciones desplegadas por Castillo para revelar su condición sexual dentro del aparato estatal. Esas acciones corresponden a fases del proceso de visibilizar su identidad sexual hasta contraer el AUC, por lo que se puede observar una organización léxica de composición que se inicia con las fases "salió del closet" y "se convirtió en la primera persona del aparato estatal en contraer el AUC”. Además, desde la voz de Castillo, advertimos procesos relacionales que introducen cualidades para reforzar su identidad ("no soy novio, sino que somos novias"), como una forma de alegar respeto hacia esa identidad no reconocida por la empresa. Asimismo, la voz autoral se refiere a que, a pesar del conflicto con Falabella, Castillo persiste en su propósito de contraer el AUC ("sigue adelante con los preparativos para la ceremonia") y realza la ceremonia a través de alusiones a las características de sus invitados ("ya tiene sus invitados VIP"). La tabla 8 ilustra las fases del proceso de visibilizar la identidad sexual de Castillo hasta los preparativos de la ceremonia de AUC. 
Tabla 8. Proceso de visibilizar la orientación sexual de la funcionaria de INJUV

\begin{tabular}{|c|c|c|c|}
\hline \multicolumn{4}{|c|}{ Proceso de visibilizar la identidad sexual } \\
\hline \multirow{5}{*}{$\begin{array}{l}\text { Identidad } \\
\text { sexual Camila } \\
\text { Castillo }\end{array}$} & Instancias textuales & Relaciones taxonómicas & Voces \\
\hline & $\begin{array}{l}\text { Salió del closet } \\
\text { Se convirtió en la primera } \\
\text { persona del aparato estatal en } \\
\text { contraer el AUC }\end{array}$ & \multirow[t]{4}{*}{$\begin{array}{c}\text { Composición. } \\
\text { Fases del proceso de } \\
\text { visibilizar su identidad sexual }\end{array}$} & Voz autoral \\
\hline & $\begin{array}{l}\text { No soy novio, sino que somos } \\
\text { novias }\end{array}$ & & $\begin{array}{l}\text { Camila Castillo, } \\
\text { funcionaria de } \\
\text { INJUV }\end{array}$ \\
\hline & $\begin{array}{l}\text { Sigue adelante con los } \\
\text { preparativos para la ceremonia }\end{array}$ & & \\
\hline & Ya tiene sus invitados VIP & & Voz autoral \\
\hline
\end{tabular}

Se agregan a los casos anteriores, el maltrato propinado a un trabajador gay por parte de la empresa Ripley. El brutal caso de discriminación homofóbica fue publicado por el medio de ciberprensa El Ciudadano. Las representaciones discursivas prominentes respecto a Carlos Seaone se articulan desde taxonomías de cualidades y procesos. En la siguiente tabla se organizan las cualidades atribuidas al trabajador desde las voces del agresor, el supervisor Rodrigo González. Las cualidades identificadas en la voz del supervisor se pueden organizar en las dimensiones "condena" y "supuestas predilecciones" de los gays. En efecto, las cualidades condenatorias expresadas por el supervisor se relacionan por sinonimia y concuerdan con aquellas que históricamente se han empleado para reproducir la condena a los gays ("hueco", "cola”, "maricón", "gay"). Adicionalmente, el supervisor complementa esa descripción insultante mediante frases adjetivas que aluden a una creencia acerca de las supuestas predilecciones sexuales gays ("ponte ready", "te gusta que te rompan el hoyo"). Esas cualidades se relacionan por co-hiponimia, en tanto corresponden a tipos de predilecciones. La tabla 9 da cuenta de las cualidades condenatorias atribuidas a Seaone y que construyen la identidad sexual del trabajador.

Tabla 9. Identidad sexual del trabajador de la empresa Ripley.

\begin{tabular}{|l|l|c|c|}
\hline \multicolumn{3}{|c|}{ Identidad sexual } \\
\hline \multirow{2}{*}{ Carlos Seaone } & Instancias textuales & \multicolumn{1}{|c|}{$\begin{array}{c}\text { Relaciones } \\
\text { taxonómicas }\end{array}$} & Voz \\
\cline { 2 - 4 } & $\begin{array}{l}\text { Hueco } \\
\text { Cola } \\
\text { Maricón } \\
\text { Gay }\end{array}$ & Sinonimia & $\begin{array}{c}\text { Supervisor Rodrigo } \\
\text { González }\end{array}$ \\
\cline { 2 - 3 } & $\begin{array}{l}\text { Ponte ready } \\
\text { Te gusta que te rompan } \\
\text { el hoyo }\end{array}$ & $\begin{array}{c}\text { Hiperónimo } \\
\text { Predilecciones } \\
\text { Co-hiponimia } \\
\text { Tipos de predilecciones }\end{array}$ & \\
\hline
\end{tabular}

\subsection{El rol político de las organizaciones y sus dirigentes}

En el medio de ciberprensa La Cuarta, en el contexto del caso Zamudio, puedo reconocer procesos materiales asociados al Movilh relacionados por sinonimia y que dan cuenta de sus gestiones políticas y vínculos con el poder institucional ([Una querella] interpuso el Movilh", "Movilh e intendencia chantan ${ }^{6}$ querellas contra responsables de salvaje ataque"), como se puede apreciar en la tabla 10: 
Tabla 10. Gestión política de Movilh

\begin{tabular}{|c|c|c|c|}
\hline \multicolumn{4}{|c|}{ Gestión política del Movilh } \\
\hline \multirow{3}{*}{$\begin{array}{c}\text { Gestión política del } \\
\text { Movilh }\end{array}$} & Instancias textuales & $\begin{array}{c}\text { Relaciones } \\
\text { taxonómicas }\end{array}$ & Voz \\
\hline & $\begin{array}{l}\text { Movilh e Intendencia } \\
\text { chantan querella contra } \\
\text { responsables del salvaje } \\
\text { ataque }\end{array}$ & \multirow[t]{2}{*}{ Sinonimia } & \multirow[t]{2}{*}{ Voz autoral } \\
\hline & $\begin{array}{l}\text { (querella) interpuso el } \\
\text { Movilh }\end{array}$ & & \\
\hline
\end{tabular}

Las voces autorales resaltan la gestión política del Movilh a través de procesos verbales y materiales ("Movilh anuncia querella con ley Zamudio", "Interpondrán acciones legales contra quienes resulten responsables..."). Estos procesos construyen discursivamente la gestión política del organismo y se relacionan por co-hiponimia, pues corresponden a tipos de acciones ejecutadas o por ejecutar. Los procesos se realizan proyectados al futuro y perfilan el cometido del organismo. Esa proyección de las gestiones políticas del Movilh, se aprecia también en su propia voz. En efecto, mediante procesos materiales delinean sus próximas acciones en respuesta al asesinato de Zamudio ("agotaremos todas las diligencias que sean necesarias para que este ataque no quede impune", "presentaremos acciones legales y pediremos al ministerio del interior que se sume también con su propia querella..."). En las instancias anteriores, el proceso "agotar" conlleva el significado de perseverancia y persistencia en la gestión para conquistar justicia. Esas taxonomías de procesos se pueden observar en la tabla 11:

Tabla 11. Gestión e incidencia política del Movilh

\begin{tabular}{|c|c|c|c|}
\hline \multicolumn{4}{|c|}{ Gestión política de Movilh } \\
\hline \multirow{3}{*}{$\begin{array}{c}\text { Gestión } \\
\text { política e } \\
\text { influencia } \\
\text { institucional } \\
\text { del Movilh }\end{array}$} & Instancias textuales & $\begin{array}{c}\text { Relaciones } \\
\text { taxonómicas }\end{array}$ & Voces \\
\hline & $\begin{array}{l}\text { Movilh anuncia querella con ley } \\
\text { Zamudio } \\
\text { Interpondrán acciones legales contra } \\
\text { quienes resulten responsables }\end{array}$ & \multirow{2}{*}{$\begin{array}{c}\text { Hiperónimo } \\
\text { Acciones políticas } \\
\text { Co-hiponimia } \\
\text { Tipos de acciones } \\
\text { políticas }\end{array}$} & Voz autoral \\
\hline & $\begin{array}{l}\text { Agotaremos todas las diligencias } \\
\text { que sean necesarias para que este } \\
\text { ataque no quede impune } \\
\text { Presentaremos acciones legales } \\
\text { Pediremos al ministerio del interior } \\
\text { que se sume } \\
\text { Demandaremos que se revisen todas } \\
\text { las cámaras de seguridad }\end{array}$ & & Movilh \\
\hline
\end{tabular}

En el cuadro siguiente podemos apreciar la construcción discursiva del compromiso político de las organizaciones Movilh e Iguales a través de actividades que se relacionan por co-hiponimia, cuyo hiperónimo correspondería a "actividad política". Ese compromiso político se realiza a través del proceso material "fue seguida", en el caso del medio de ciberprensa La Tercera.

En El Ciudadano, por su parte, se mencionan un conjunto de organizaciones de diversidad sexual a las que se les atribuye la realización de actividades para impulsar la legislación contra la discriminación. En este sentido, el proceso material "realizarán", el proceso mental "concientizar", el proceso mental "esperan" y el proceso verbal "argumentan" ilustran la gestión política de las organizaciones en orden a contribuir en el plano de la educación para lo 
no discriminación y, por consiguiente, impulsar la tramitación de la ley.

En definitiva, ambos medios de ciberprensa acentúan en el rol político de la organización. La Tercera sitúa ese rol político en el ámbito institucional, mientras que El Ciudadano lo ubica fuera de los márgenes institucionales. La tabla 12 muestra los procesos que configuran la gestión política del organismo.

Tabla 12. Gestión política de Iguales.

\begin{tabular}{|c|c|c|c|}
\hline \multicolumn{4}{|c|}{ Gestión política de Iguales } \\
\hline & Instancias textuales & $\begin{array}{l}\text { Relaciones } \\
\text { taxonómicas }\end{array}$ & Voz \\
\hline $\begin{array}{l}\text { Gestión } \\
\text { política de } \\
\text { Iguales }\end{array}$ & $\begin{array}{l}\text { La votación fue seguida por el } \\
\text { Movilh, fundación Iguales, entre otras } \\
\text { organizaciones } \\
\text { Realizarán una serie de actividades } \\
\text { que tienen como objetivo concientizar } \\
\text { a la población sobre distintos tipos } \\
\text { de discriminación, la tolerancia y el } \\
\text { respeto a la diversidad } \\
\text { Esperan que se apuren los trámites de } \\
\text { la ley antidiscriminación } \\
\text { Argumentan que es clave para evitar } \\
\text { hechos como el ocurrido a Daniel }\end{array}$ & $\begin{array}{c}\text { Hiperónimo } \\
\text { Actividad política } \\
\text { Co-hipónimos } \\
\text { Tipos de actividades } \\
\text { políticas }\end{array}$ & Voz autoral \\
\hline
\end{tabular}

La inusitada violencia practicada contra Zamudio y la presión política ejercida por actores sociales políticos, obligó al gobierno de Piñera (2010-2014) a poner urgencia a la tramitación de la Ley Antidiscriminación. Tras su aprobación, Jiménez actualizó algunos datos reveladores de violencia por orientación sexual e identidad de género. La voz del dirigente es visibilizada por el medio de ciberprensa La Nación. Los procesos construyen discursivamente el proceso social generador de la Ley Zamudio y las fases o etapas que lo constituyen. Los procesos si bien no aluden directamente a las instituciones políticas, dejan entrever su responsabilidad en el retraso de la legislación por no hacerse cargo concretamente del problema de la violencia discriminatoria. A su vez, los procesos dejan en evidencia las repercusiones del vacío legal en la sociedad chilena, como se puede advertir en la tabla 13.

Tabla 13. Proceso social de la Ley Antidiscriminación desde la voz de Rolando Jiménez

\begin{tabular}{|c|c|c|c|}
\hline \multicolumn{4}{|c|}{ Proceso social de la Ley Antidiscriminación } \\
\hline \multirow{2}{*}{$\begin{array}{c}\text { Proceso social } \\
\text { de la ley }\end{array}$} & $\begin{array}{c}\text { Relaciones } \\
\text { taxonómicas }\end{array}$ & Voz \\
\cline { 2 - 4 } Antidiscriminación textuales & $\begin{array}{l}\text { habido 823 casos de } \\
\text { discriminación, algunos brutales, 17 } \\
\text { asesinatos basados en la orientación } \\
\text { sexual e identidad de género } \\
\text { Ese es el costo que ha pagado Chile } \\
\text { para tener una ley antidiscriminación }\end{array}$ & $\begin{array}{c}\text { Composición } \\
\text { Fases del proceso } \\
\text { social }\end{array}$ & $\begin{array}{c}\text { Rolando } \\
\text { Jiménez, } \\
\text { dirigente de } \\
\text { Movilh }\end{array}$ \\
\hline
\end{tabular}

El proceso existencial "ha habido" actualiza la enorme cantidad de casos de discriminación. Dentro de esos casos, resalta el número de asesinatos por orientación sexual e identidad de género. Las causas de esos asesinatos son codificadas por el proceso "basados", pues éste alude a las motivaciones de esos crímenes. El proceso relacional "es" hace referencia a que esos guarismos definen el enorme precio pagado por la sociedad chilena a causa del vacío legal y nulo compromiso político institucional para legislar al respecto. El proceso material "ha pagado" revela las repercusiones humanas de la carencia de una legislación contraria a la discriminación. 
Otras representaciones discursivas respecto a la trama institucional provienen de la voz de la organización que Jiménez representa. Desde la voz del Movilh, en el medio de ciberprensa El Ciudadano, se manifiesta la molestia contra el Gobierno debido a la postergación del envío al Congreso del proyecto de Matrimonio Igualitario.

Las críticas del organismo a las instituciones del Estado también se orientan a la gestión de la presidenta Bachelet. Esta gestión es contrastada con el desempeño del presidente Piñera y su Gobierno al tramitar la Ley Antidiscriminación y el Acuerdo de Unión Civil. La tabla 14 muestra los procesos que construyen los incumplimientos de la mandataria y su Gobierno desde la voz del Movilh. Esos procesos se relacionan por co-hiponimia y revelan distintas formas de ejecutar esos incumplimientos.

Tabla 14. Gestión política de Bachelet y su gobierno desde la voz del Movilh.

\begin{tabular}{|c|c|c|c|c|}
\hline \multicolumn{5}{|c|}{ Gestión política de Bachelet y su Gobierno } \\
\hline & Instancias textuales & Relacione & taxonómicas & Voz \\
\hline $\begin{array}{c}\text { Construcción } \\
\text { discursiva de los } \\
\text { incumplimientos } \\
\text { de Bachelet }\end{array}$ & $\begin{array}{l}\text { Pareciera ser que para } \\
\text { Bachelet con la unión civil basta } \\
\text { y sobra } \\
\text { Se equivoca, más al recordar } \\
\text { que este proyecto fue } \\
\text { compromiso no cumplido en } \\
\text { su primer Gobierno } \\
\text { Ya durante su primer Gobierno } \\
\text { Bachelet postergó nuestros } \\
\text { derechos yo cumplió ninguna } \\
\text { de sus promesas electorales, } \\
\text { como la unión civil. Ahora va } \\
\text { por el mismo camino }\end{array}$ & $\begin{array}{l}\text { Repetición (no } \\
\text { cumplido, no } \\
\text { cumplió) }\end{array}$ & $\begin{array}{c}\text { Hiperónimo } \\
\text { Incumplimientos } \\
\text { Co-hipónimos } \\
\text { Tipos de } \\
\text { incumplimientos }\end{array}$ & Movilh \\
\hline
\end{tabular}

La instancia "pareciera ser" funciona como proceso relacional en tanto introduce el significado de "suficiente" para referirse al Acuerdo de Unión Civil. Específicamente, el proceso "pareciera" sugiere una especulación por parte del organismo respecto a la actitud de Bachelet. Si esa es la actitud de la mandataria, para el Movilh, entonces, "se equivoca". Este proceso cumple la función no solo de acusar a Bachelet, sino también de incorporar las razones de ese equívoco. Esas razones se sostienen en el proceso relacional "fue" y en el proceso material "no cumplido" que aluden al compromiso suscrito por Bachelet en su primera administración (2006-2010) y que no fue concretado. El Movilh nos recuerda que fue el Gobierno de Piñera el que impulsa la tramitación de algunas de las demandas ("Finalmente fue enviada por el presidente Piñera"). El organismo, además, actualiza lo sucedido durante la primera administración de Bachelet y formula críticas a su gestión a través de procesos materiales "no cumplió" y "postergó”. Luego de esa actualización, el Movilh denuncia que "ahora va por el mismo camino". Esta instancia da cuenta del comportamiento político de la mandataria en materia de derechos humanos de la diversidad sexual. El proceso "va" funciona como proceso material que alude a una acción similar a la realizada en el primer Gobierno.

En el medio de ciberprensa El Mostrador, la voz de Larraín, dirigente de Iguales, aborda las repercusiones sociales del AUC y se refiere a la posible pérdida de predominio del matrimonio como institución social. La tabla 15 ilustra los procesos que construyen la relevancia personal y social de la ley de AUC. Esos procesos representan las fases o etapas que conforman el procesamiento interior de las personas gay al enfrentar la marginación social. 
Tabla 15. Relevancia social del Acuerdo de Unión Civil desde la voz de Luis Larraín

\begin{tabular}{|c|c|c|c|c|}
\hline \multicolumn{5}{|c|}{ Representación discursiva del AUC } \\
\hline \multirow{4}{*}{$\begin{array}{c}\text { Instancias textuales } \\
\text { Relevancia } \\
\text { personal y } \\
\text { social del } \\
\text { AUC }\end{array}$} & $\begin{array}{l}\text { Es tremendamente emocionante para } \\
\text { quienes hemos sentido la marginación } \\
\text { de la sociedad, incluso hemos luchado } \\
\text { contra nosotros mismos, con intentos } \\
\text { de relaciones heterosexuales, } \\
\text { Para esos gays y lesbianas de la tercera } \\
\text { edad que se han sentido marginados } \\
\text { de la sociedad }\end{array}$ & Repetición & $\begin{array}{c}\text { Composición } \\
\text { Fases }\end{array}$ & $\begin{array}{c}\text { Luis Larraín, } \\
\text { presidente de } \\
\text { Iguales }\end{array}$ \\
\hline
\end{tabular}

El proceso relacional "es" introduce la valoración afectiva respecto a la promulgación de la ley ("es tremendamente emocionante"). La significación de dicha promulgación la sitúa en la comunidad gay. Desde la primera persona plural del proceso "hemos sentido", la voz del dirigente configura la significación social del AUC para la comunidad gay (...para quienes hemos sentido la marginación de la sociedad”). Esa marginación experimentada motiva, según Larraín, un conflicto interno en quienes la viven. Ese conflicto interno generado por la hostilidad social es codificado por el proceso "hemos luchado". Este proceso revela cómo la marginación social arrastra a los gays a renegar de su identidad para ser aceptados ("incluso hemos luchado contra nosotros mismos, con relaciones heterosexuales...”). Dentro de las personas marginadas por la sociedad, Larraín recuerda a los gays de la tercera edad quienes vivieron esa marginación en un contexto social y cultural mucho más hostil ("Para esos gays y lesbianas de la tercera edad que se han sentido marginados de la sociedad").

En síntesis, el siguiente diagrama ilustra la participación de las entidades colectivas e individuales de la comunidad gay en la construcción de la experiencia en el mundo social. Si bien el diagrama muestra la victimización de la comunidad gay y su rol social pasivo, cabe consignar que las taxonomías de procesos verbales y materiales asociados a la pareja lésbica, la funcionaria de INJUV Camila Castillo y el trabajador de Ripley Carlos Seaone, revelan su agencialidad en las denuncias de discriminación homofóbica y las acciones emprendidas para enfrentarla.

En relación con el rol social de víctima de Daniel Zamudio, no solo se acentúa la discriminación homofóbica asesina, sino también las formas de representación discursiva que revelan una tensión entre su identidad social y su identidad sexual. Esa tensión identitaria radica en que su manera de ser en el mundo social intenta ser presentada, de un lado, a partir de la normalidad, pues tiene aspiraciones y realiza actividades como cualquier persona y, por otro lado, desde su diferencia sexual.

La participación de la comunidad gay representada por los medios de ciberprensa devela su incidencia en el mundo social. La victimización de la comunidad gay, a partir del Caso Zamudio, visibiliza el fenómeno sociocultural de la homofobia en sus distintas expresiones e impulsa la gestión política y comunicacional de las organizaciones sociales Movilh e Iguales y sus dirigentes. Sin embargo, la construcción discursiva de la gestión política y comunicacional de esos organismos y dirigentes tiene distintos grados de aparición. En relación con el Caso Zamudio la aparición del Movilh y sus dirigentes es mucho más prominente; mientras que, en materia de legislación, emerge la incidencia política de Iguales de manera más equilibrada con el Movilh.

En definitiva, la participación de la comunidad gay puede sintetizarse en la categoría ideológica "gay político" en sus dimensiones "víctima" y "agente de transformación social". Las denuncias de las víctimas y las repercusiones sociales de la victimización impulsan la gestión política de las organizaciones de diversidad sexual y sus principales dirigentes. Desde esas denuncias de las víctimas, las organizaciones y sus dirigentes activan procesos políticos y comunicacionales para 
relevar sus agendas y capacidad de interlocución frente a las autoridades políticas institucionales. Por consiguiente, la articulación de las dimensiones "víctima" y "agente de transformación social" constituiría un dispositivo de poder con incidencia en la discusión pública difundida por la ciberprensa examinada. La aparición de la categoría ideológica "gay político", por tanto, ilustra los cambios sociales experimentados por la sociedad chilena en la década recién finalizada, en materia de tratamiento público de la comunidad gay. A continuación se presenta el diagrama anunciado.

Figura 2. Participación en el mundo social de entidades colectivas e individuales de la comunidad gay.

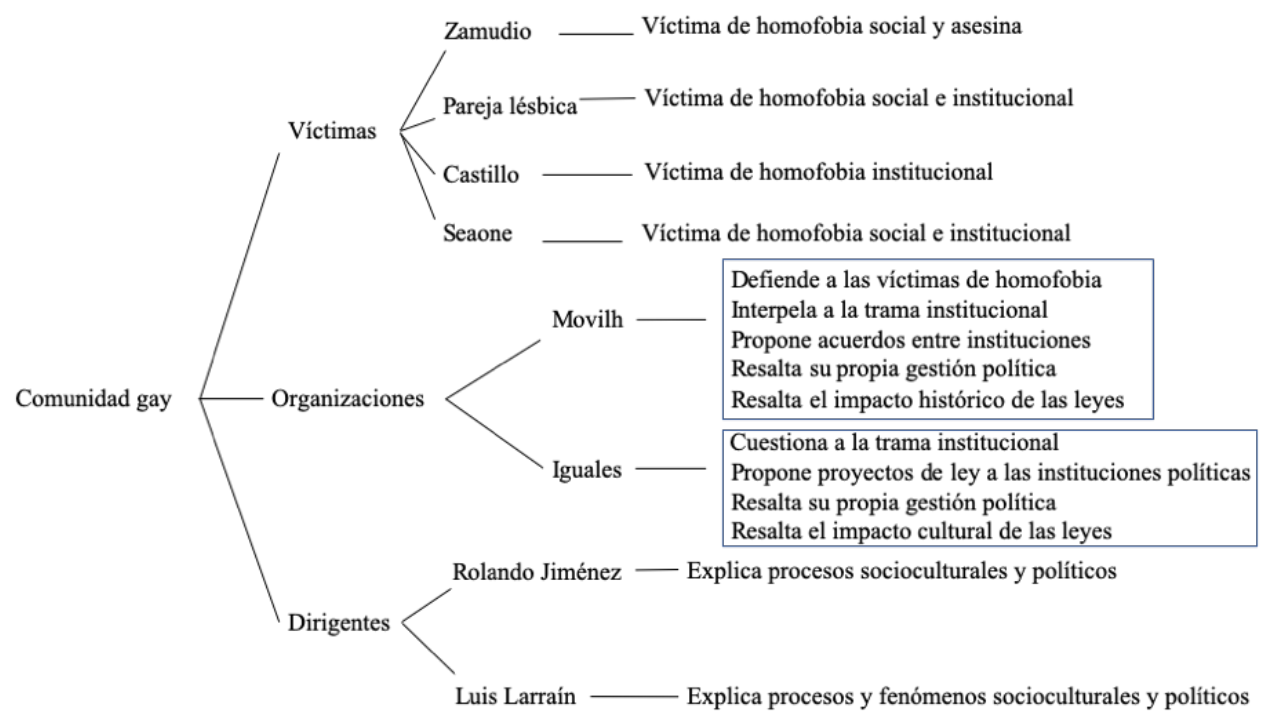

La emergencia del dispositivo de poder "gay político" evidencia un nuevo estadio en las relaciones de poder en tanto complementan la trayectoria léxica que, según Contardo (2011), resume la historia del tratamiento a la homosexualidad en Chile: "sodomita", "invertido", "maricón", "homosexual" y "gay".

Si bien la unidad léxica "gay" históricamente no contiene una carga semántica vergonzante, aún es homologada a las demás y empleada para sancionar la diferencia por orientación sexual, tal como lo muestra una de las instancias textuales presentada en la tabla 9. En ese caso, se representa el ataque de un supervisor de la tienda Ripley contra un trabajador. En ese ataque se recurre a un amplio repertorio de unidades léxicas empleadas en Chile para aludir peyorativamente a las personas gays ("hueco", "cola", "maricón", "gay"). Probablemente, la acumulación de esos recursos en el ataque, la referencia a supuestas conductas predilectas de las personas gays y el intento de deslegitimar y excluir al trabajador, otorgue una connotación negativa a la unidad léxica "gay". Esto significa que dicha connotación negativa estaría anclada al evento o situación comunicativa representada en el texto de ciberprensa.

\section{Conclusiones}

La comunidad gay es representada en los medios de ciberprensa como víctima de la violencia homofóbica y agente de la transformación social. Precisamente su condición de víctima moviliza la gestión política de las organizaciones Movilh e Iguales y a sus principales dirigentes, Rolando Jiménez y Luis Larraín, respectivamente.

La trayectoria metodológica desplegada a partir del análisis valorativo permitió, en una 
primera fase, identificar tanto las entidades discursivas representativas de la comunidad gay evaluadas como sus voces prominentes en los textos examinados. La detección de estos aspectos interaccionales garantizó focalizar el análisis ideacional posterior, es decir, acotar la muestra para observarla desde el prisma del flujo de la experiencia. De este modo, se articuló un dispositivo metodológico funcional a la exploración del rol jugado por la comunidad gay en el mundo social configurado en los textos.

El análisis ideacional de los textos ofrece un mapeo del mundo social dibujado en torno a los hitos sociohistóricos incluidos en este estudio. En efecto, la relación entre las entidades colectivas e individuales representadas y los procesos y cualidades asociados a esas entidades entrega antecedentes acerca del rol social y político visibilizado en los textos. En este sentido, la aplicación del sistema de IDEACIÓN en la interpretación social del discurso resulta productiva para explorar la relación entre el cambio social y el cambio lingüístico, pues los recursos lingüísticos construyen una representación discursiva en la cual la comunidad gay adopta una agencialidad política que reivindica derechos al interpelar a la sociedad y sus instituciones. Esa agencialidad política difiere de las representaciones discursivas vehiculadas en otros momentos de la historia de Chile. En esos otros momentos y escenarios discursivos, la comunidad gay era sancionada por su diferencia y su peligrosidad al, supuestamente, afectar el orden social (ver Robles, 2008; Acevedo \& Elgueta, 2009; Contardo, 2011; Asalazar, 2017; Farías, 2015; Farías \& Clavijo, 2017).

La relevancia social de las relaciones taxonómicas radica en cómo construyen procesos y fenómenos socioculturales reveladores del cambio social. Las relaciones taxonómicas mostradas en los ejemplos evidencian procesos socioculturales y la gestión política de las organizaciones y sus dirigentes. Los procesos socioculturales dan cuenta de las repercusiones de la legislación; mientras que la gestión política devela la incidencia política de las organizaciones, las cuales no solo denuncian la responsabilidad de las autoridades e instituciones en el tratamiento discriminatorio, sino también proponen proyectos para mejorar las legislaciones existentes. Las víctimas cumplen un rol político clave en la transformación de las relaciones de poder. Ellas visibilizan las distintas formas de violencia y al realizarlo abren paso a la incidencia de las organizaciones y sus dirigentes. Por tanto, se podría especular con una emergente categoría ideológica: gay político. Este "gay político" opera en dos dimensiones, como "víctima” y como "agente de transformación social".

El estudio, en consecuencia, demuestra que estamos en presencia de un nuevo estadio de inestabilidad en las relaciones de poder entre los grupos hegemónicos heteronormados (Pollak, 1987; Preciado, 2002; Wittig, 2016) y el movimiento político de diversidad sexual, sus organizaciones y dirigentes. La manera de representar a la comunidad gay en el corpus demuestra aquel reajuste en las relaciones de poder. Esto supone una nueva configuración de las estructuras sociales y, por lo tanto, novedosos órdenes del discurso (Foucault, 1973; Silverstone, 1999; Fairclough, 1992, 1995, 2013, 2014), en los cuales se aprecian movimientos de significados, articulados por recursos lingüísticos que difieren de los empleados en la construcción de la condena y repudio contra las sexualidades disidentes y, particularmente, contra la comunidad gay. El cambio discursivo observado en las formas de representación de la comunidad gay se alinea con los cambios legales producidos en los últimos años en Chile. Probablemente estemos en presencia de fisuras en el discurso hegemónico condenatorio.

\section{Agradecimientos y financiamiento}

El trabajo fue realizado con el respaldo de beca Conicyt para doctorado nacional. El artículo presenta algunos de los resultados de la tesis doctoral: "Concepciones ideológicas acerca de la comunidad gay desde sus representaciones discursivas en textos de ciberprensa chilena". Esta investigación fue realizada en el programa de doctorado en lingüística de la Facultad de Letras de la Pontificia Universidad Católica de Chile. 


\section{Referencias bibliográficas}

Academia Chilena de la Lengua. (2010). Diccionario de uso del español de Chile. Santiago: MN Editorial.

Acevedo, C. \& Elgueta, E. (2009). El discurso homofóbico en la prensa izquierdista durante la Unidad Popular. Revista Izquierdas, 2 (3), 1-12.

Alegre, L. (2017). Elogio de la homosexualidad. Barcelona: Arpa Editores.

Asalazar, G. (2017). Deseo invisible. Santiago cola antes del golpe. Santiago. Cuarto Propio.

Cabrera, M. (2010). Evolución tecnológica y cibermedios. Sevilla: Comunicación Social Ediciones y Publicaciones.

Castells, M. (2006). La Era de la Información: Economía, sociedad y cultura, Vol. I y III México: Siglo XXI Editores.

Chamocho, M. (2012). Sodomía. El crimen y pecado contra natura o historia de una intolerancia. Madrid: Dykinson.

Contardo, Ó. (2011). Raro. Una historia gay de Chile. Santiago. Planeta.

Fairclough, N. (1992). Discourse and social change. Cambridge: Polity Press.

Fairclough, N. (1995). Critical Discourse Analysis. Londres: Longman.

Fairclough, N. (2013). Critical discourse analysis. The critical study of language. Second Edition. New York: Routledge.

Fairclough, N. (2014). Critical Discourse Analysis. En P. Gee \& M. Handford (Eds.), The Routledge Handbook of discourse analysis. London: Routledge

Farías, M. (2015). Análisis crítico multimodal y percepción del discurso homofóbico en el paisaje sociosemiótico de Santiago de Chile. Revista ALED. Edición homenaje 20 años.

Farías, M. \& Clavijo, A. (2017). Análisis exploratorio de discurso homofóbico multimodal en Santiago de Chile y Bogotá. Discurso y Sociedad, 11(1), 47-69.

Fone, B. (2008). Homofobia. Una historia. México: Océano.

Foucault, M. (1973). El orden del discurso. Buenos Aires: Tusquets.

Halliday, M. \& Matthiessen, C. (2014). An introduction to functional grammar. Quarter edition. New York: Oxford University Press.

Lario, M. (2008). La representación de la inmigración y de los inmigrantes en la prensa y en la radio. Estado de la cuestión. En A. Bañón \& J. Fornieles (Eds.), Manual sobre comunicación e inmigración (pp. 195-214). Donosita-San Sebastián: Gakoa Liburuak.

Martin, J. (1992). English text: system and structure. Filadelfia: John Benjamins.

Martin, J. (2003). Introduction. Text, 23(2), 171-181.

Martin, J. \& White, P. (2005). Language of the Evaluation. Appraisal in English. Ney York: Palgrave Macmillan. 
Martin, J. \& Rose, D. (2007). Working with discourse. Meaning beyond the clause. London, New York: Continuum.

Martel, F. (2013). Global gay. Cómo la revolución gay está cambiando el mundo. México: Taurus.

Pollak, M. (1987). La Homosexualidad Masculina o ¿La Felicidad en el Ghetto?. En Sexualités occidentales. Paidós: Buenos Aires.

Preciado, B. (2002). Manifiesto contra-sexual. Madrid: Editorial Ópera Prima.

Robles, V. (2008). Bandera hueca. Santiago: Cuarto Propio.

Silverstone, R. (1999). Why study the media? London: Sage.

Trejo, R. (1996). La nueva alfombra mágica. Usos y mitos de Internet, la red de redes. México: Editorial Diana.

Wittig, M. (2016). El pensamiento heterosexual. Barcelona: Egales.

Zubiaur, I. (2007). Pioneros de lo homosexual. Barcelona: Anthropos.

\section{Notas}

1. El concepto de trama institucional puede definirse como la alianza o asociación coludida entre diversas instituciones de poder.

2. Este diagrama sintetiza los planteamientos de Martin (1992) respecto a las relaciones taxonómicas. Las categorías repetición, sinonimia, contraste y clase corresponden a las relaciones taxonómicas por subordinación; mientras que las categorías parte y co-parte refieren a las relaciones taxonómicas por composición.

3. Dirigente del Movimiento de Integración y Liberación Homosexual (Movilh).

4. Presidente de Fundación Iguales (2013-2017).

5. Las tablas que registran las instancias textuales, las relaciones taxonómicas y las voces son de elaboración propia

6. En el español de Chile, el término chantar significa, en una de sus acepciones, "poner en un lugar en forma brusca" (DUECh, 2010).

7. El término "gay" no contiene una connotación semántica vergonzante, a diferencia de los otros términos. La palabra "gay" no se refiere a una práctica sexual determinada o a usos específicos del cuerpo, sino más bien a un talante de ánimo (Zubiaur, 2007; Fone, 2008; Contardo, 2011). 